\title{
Deactivation Mechanism of Palladium Catalysts for Ethanol Conversion to Butanol
}

\author{
D. I. Ezzhelenko ${ }^{a}$, S. A. Nikolaev ${ }^{a, *}$, A. V. Chistyakov ${ }^{b}$, P. A. Chistyakova ${ }^{b}$, and M. V. Tsodikov ${ }^{b}$ \\ ${ }^{a}$ Lomonosov Moscow State University, Moscow, 119001 Russia \\ ${ }^{b}$ Topchiev Institute of Petrochemical Synthesis, Russian Academy of Sciences, Moscow, 119910 Russia \\ *e-mail: serge2000@rambler.ru
}

Received December 22, 2020; revised January 10, 2021; accepted March 18, 2021

\begin{abstract}
APd} / \mathrm{Al}_{2} \mathrm{O}_{3}$ catalyst $(\mathrm{Pd}=0.1 \mathrm{wt} \%)$ for ethanol conversion to butanol deactivates within $10 \mathrm{~h}$ of service, despite its high initial activity at $275^{\circ} \mathrm{C}$. Probable deactivation mechanisms were explored, including poisoning of $\mathrm{Pd} / \mathrm{Al}_{2} \mathrm{O}_{3}$ due to adsorption of by-products on $\mathrm{Pd}$, sintering of $\mathrm{Pd}$ phases, leaching of $\mathrm{Pd}$ from the catalyst, changes in the $\mathrm{Pd}$ electronic state, changes in the catalyst's porous structure, and blockage of $\mathrm{Al}_{2} \mathrm{O}_{3}$ active sites. The $\mathrm{Pd} / \mathrm{Al}_{2} \mathrm{O}_{3}$ deactivation was found to be mainly caused by $\mathrm{CO}$ molecules that evolved during side reactions. These molecules can either block Pd active sites due to the formation of strong $\mathrm{Pd}-\mathrm{CO}$ complexes, or enter a $\mathrm{CO}$ disproportionation reaction to form carbon deposits on Pd phases. The knowledge gained from this study can be used for the targeted modification of $\mathrm{Pd} / \mathrm{Al}_{2} \mathrm{O}_{3}$ and the creation of selective systems operating stably in the presence of by-products.
\end{abstract}

Keywords: nanoparticles, synergism, butanol, ethanol, catalysis

DOI: $10.1134 / \mathrm{S} 0965544121050017$

Bioethanol is one of the few substances produced from natural and rapidly renewable raw materials using a wellproven technology [1,2]. Ethanol has usually been used as an additive to engine fuels. Currently, the volumes of ethanol consumption in the transport sector have lagged significantly behind those of ethanol production. In 2017-2020, the surplus of bioethanol production capacity amounted to $3 \times 10^{10} \mathrm{~L} /$ year. Therefore, bioethanol can be considered as an available substrate for the development of novel technologies for the production of valuable synthetic hydrocarbons, including butanol.

Butanol has been used for the synthesis of antibiotics, vitamins, and esters [3]. It is worth noting that butanol releases more energy during combustion than ethanol. This makes butanol a more effective additive to engine fuels and, thus, a very promising material for the automotive industry.

Published reports describe two main mechanisms of ethanol conversion to butanol $[4,5]$. At $350-450^{\circ} \mathrm{C}$, acid-base catalysts promote the bimolecular condensation of ethanol into butanol (mechanism I). In contrast to acid-base catalysts, supported catalysts promote butanol production at lower temperature $\left(200-300^{\circ} \mathrm{C}\right)$ through a number of steps depicted in Fig. 1 (mechanism II). Thus, supported catalysts can be considered a more energyefficient solution for ethanol conversion to butanol.

A typical supported ethanol conversion catalyst is denoted as M/Support, where $\mathrm{M}$ refers to a metal (e.g., $\mathrm{Pd}, \mathrm{Pt}, \mathrm{Ni}, \mathrm{Cu}$, etc.), and Support is represented by, for example, $\mathrm{Al}_{2} \mathrm{O}_{3}, \mathrm{MgO}-\mathrm{Al}_{2} \mathrm{O}_{3}, \mathrm{CaO}-\mathrm{Al}_{2} \mathrm{O}_{3}$, etc. In such systems, the metal $(\mathrm{M})$ is a catalyst for the dehydrogenation and hydrogenation steps, while the acid-base sites of the support catalyze the condensation reaction (Fig. 1).

The efficiency of supported catalysts has been discussed in references [2-5]. Some relevant data are provided below.

Riittonen et al. have studied the activity of $\mathrm{M} / \mathrm{Al}_{2} \mathrm{O}_{3}$ catalysts $(\mathrm{M}=\mathrm{Pd}, \mathrm{Pt}, \mathrm{Rh}$, and $\mathrm{Ni})$ in ethanol conversion at $250^{\circ} \mathrm{C}$ [6]; the best performance was shown by $20 \% \mathrm{Ni} / \mathrm{Al}_{2} \mathrm{O}_{3}$ (ethanol conversion $25 \%$; butanol selectivity $80 \%$ ). Marcu et al. have studied the activity of $\mathrm{M} / \mathrm{Al}_{2} \mathrm{O}_{3}(\mathrm{M}=\mathrm{Pd}, \mathrm{Ag}, \mathrm{Cu}, \mathrm{Fe}$, and $\mathrm{Sm})$ in ethanol conversion at $200^{\circ} \mathrm{C}$ [7]; the best performance was 

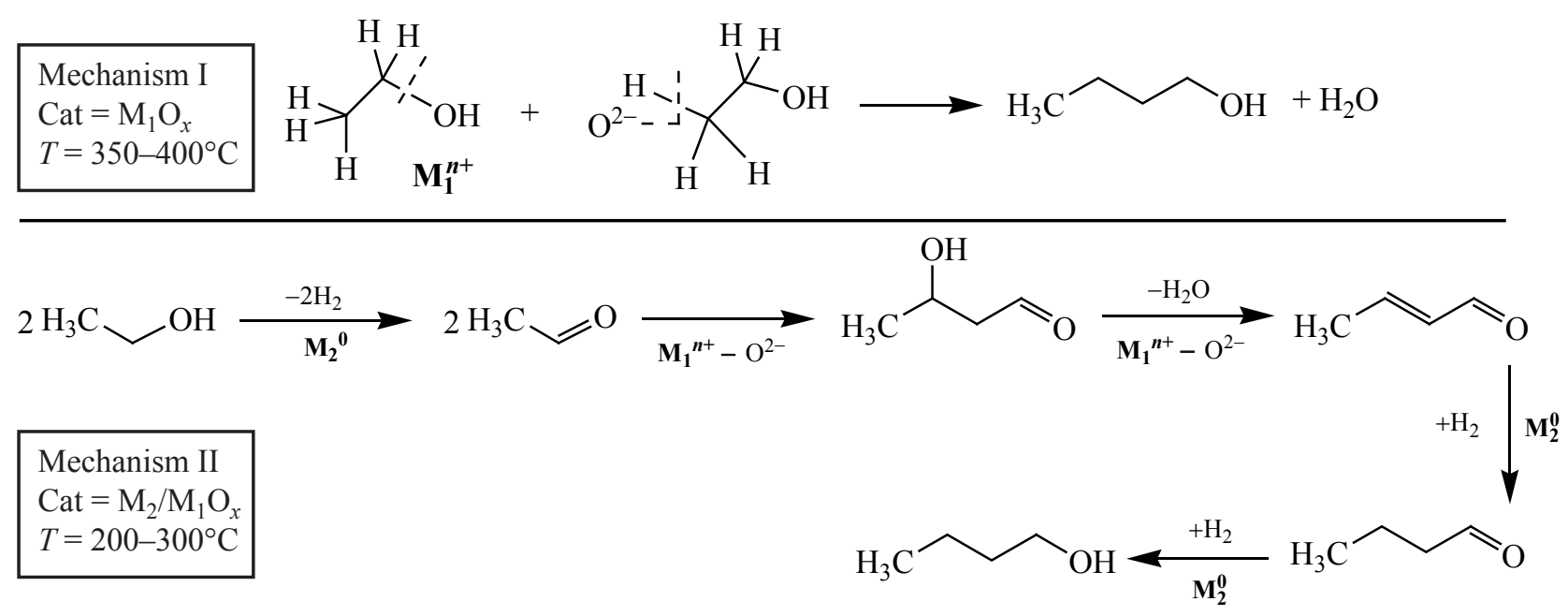

Fig. 1. Mechanisms of ethanol conversion over acid-base catalysts $\mathrm{M}_{1} \mathrm{O}_{x}\left(\mathrm{M}_{1}=\mathrm{Al}, \mathrm{Mg}, \mathrm{Ca}, \mathrm{Al}-\mathrm{Si}\right)$ and supported catalysts $\mathrm{M}_{2} / \mathrm{M}_{1} \mathrm{O}_{x}$ $\left(\mathrm{M}_{1}=\mathrm{Al}, \mathrm{Mg}, \mathrm{Ca}, \mathrm{Al}-\mathrm{Si} ; \mathrm{M}_{2}=\mathrm{Pd}, \mathrm{Ni}, \mathrm{Pt}, \mathrm{Rh}\right)[1-5]$.

demonstrated by $5 \% \mathrm{Pd} / \mathrm{Al}_{2} \mathrm{O}_{3}$ (ethanol conversion $12 \%$; butanol selectivity $70 \%$ ).

The principal challenge of supported catalysts has been their low performance stability resulting in a slowdown of the formation of target products over the course of long-term experiments [2-8]. Only a very limited number of research papers published between 2000 and 2020 have dealt with the deactivation mechanisms of ethanol conversion catalysts and with methods for their optimization.

Some researchers have noted the low stability of $\mathrm{Ni} / \mathrm{Al}_{2} \mathrm{O}_{3}$ and $\mathrm{Ni} / \mathrm{MgO}-\mathrm{Al}_{2} \mathrm{O}_{3}[6,9,10]$. The reaction was found to be accompanied by partial cracking of ethanol and organic products leading to the formation of coke precursors $\left(\mathrm{CH}_{4}, \mathrm{CO}\right.$, and $\left.\mathrm{C}_{2} \mathrm{H}_{2}\right)$. The catalyst deactivation was assumed to likely occur through coke adsorption on Ni phases. To reduce the cracking rate, nickel has been modified with copper to prepare a $\mathrm{NiCu} / \mathrm{MgO}-\mathrm{Al}_{2} \mathrm{O}_{3}$ composite (7.5 wt \% Ni, $8.2 \mathrm{wt} \% \mathrm{Cu}$ ) [10]. During the test, the $\mathrm{NiCu}$ composite demonstrated low activity in cracking, while maintaining high butanol selectivity $(76 \%)$. At the same time, the high content of the supported alloy phases used by the authors of reference [10] led to the agglomeration of $\mathrm{NiCu}$ particles. As a result, despite sustaining high selectivity, the $\mathrm{NiCu}$ catalyst was quickly sintered and lost its activity.

Compared with $\mathrm{NiCu} / \mathrm{MgO}-\mathrm{Al}_{2} \mathrm{O}_{3}, \mathrm{a} \mathrm{Cu}-\mathrm{CeO}_{2} / \mathrm{C}$ catalyst (10 wt \% Cu, 20 wt \% Ce) has shown a higher resistance to sintering [9]. Moreover, the low cracking activity of copper contributed to the catalyst's relatively low deactivation by coking on the metal surface. This had a positive impact on the $\mathrm{Cu}-\mathrm{CeO}_{2} / \mathrm{C}$ performance stability. On the other hand, in view of the high activity of $\mathrm{CeO}_{2}$ with regard to side dehydration reactions, as well as the low activity of $\mathrm{Cu}$ in dehydrogenation/hydrogenation of target intermediates, $\mathrm{Cu}-\mathrm{CeO}_{2} / \mathrm{C}$ cannot be considered as an effective catalyst. Despite the sustained high rate of ethanol conversion ( $40 \%$ ), the $\alpha$-alcohol selectivity in the presence of $\mathrm{Cu}-\mathrm{CeO}_{2} / \mathrm{C}$ does not reach above $40 \%$.

At relatively high temperatures $\left(350-450^{\circ} \mathrm{C}\right)$, the acidbase sites of ethanol conversion catalysts are deactivated $[4,11,12]$. One deactivation route involves a chemical interaction between the acid sites of oxide supports and water produced from the reaction. Some studies have also reported adsorption of by-products (specifically, ethers and heavy hydrocarbons) on the oxide surface, with a resultant decrease in the number of sites required for the ethanal condensation step to run $[4,13]$. A drop in the specific surface area of oxides during catalysis has also been reported. This drop reduces the number of active sites and is presumably the central factor in the catalyst deactivation rate [13]. The following main approaches to slow down the deactivation of acid-base sites have been suggested: optimizing the reaction conditions (by lowering the temperature, using flow-through reactors, increasing the feed flow rate, or utilizing sorbents that bind byproducts) and using specialized supports (e.g., $\mathrm{Mg}-\mathrm{AlO}_{x}$, $\mathrm{Ce}-\mathrm{ZrO}_{x}, \mathrm{~B}-\mathrm{MFI}$, etc.) [4, 11-13].

The research discussed above suggests that $\mathrm{Pd} / \mathrm{Al}_{2} \mathrm{O}_{3}$ is a promising system for ethanol conversion to butanol at 
moderate temperatures [7]. At the same time, for reasons that have not been sufficiently explored, palladium catalysts have low performance stability. This has hampered further development of modified Pd catalysts with higher performance stability.

The analysis of the reaction mechanisms (Fig. 1) leads to a general assumption that the low stability of $\mathrm{Pd} / \mathrm{Al}_{2} \mathrm{O}_{3}$ is caused by a failure of the $\mathrm{Pd}$ component and/or by a modification to the $\mathrm{Al}_{2} \mathrm{O}_{3}$ active sites during the catalyst service. This failure apparently interrupts the chain of steps for butanol formation and prevents the target product from accumulating. Based on the data provided in references [8-13], $\mathrm{Pd} / \mathrm{Al}_{2} \mathrm{O}_{3}$ deactivation likely occurs by some of the following routes: adsorption of by-products on Pd; sintering of Pd phases; leaching of Pd phases from catalyst pellets; changes in the electronic state of Pd active sites; changes in the catalyst's porous structure; and blockage of $\mathrm{Al}_{2} \mathrm{O}_{3}$ active sites.

The purpose of this study was to find the specific causes of the deactivation of a model $\mathrm{Pd} / \mathrm{Al}_{2} \mathrm{O}_{3}$ catalyst during ethanol conversion to butanol. To this end, we prepared a $\mathrm{Pd} / \mathrm{Al}_{2} \mathrm{O}_{3}$ catalyst $(\mathrm{Pd}=0.1 \mathrm{wt} \%)$, investigated the accumulation kinetics of butanol and major by-products, and undertook a study to identify the differences in the Pd catalyst structure before and after deactivation. Based on the data obtained, we tested the probable deactivation models and found the main cause of the drop in the catalyst activity.

\section{EXPERIMENTAL}

$\mathrm{A} \mathrm{Pd} / \mathrm{Al}_{2} \mathrm{O}_{3}$ catalyst $(\mathrm{Pd}=0.1 \mathrm{wt} \%)$ was prepared by the method described in reference [14]. $\mathrm{APd}\left(\mathrm{NO}_{3}\right)_{2} \cdot 2 \mathrm{H}_{2} \mathrm{O}$ sample (Aldrich) that contained $4.7 \times 10^{-4} \mathrm{~mol} \mathrm{Pd}$ was dissolved in $100 \mathrm{~mL}$ of water. Using $0.1 \mathrm{M} \mathrm{NaOH}$ (Reachem), the $\mathrm{pH}$ of the solution was brought to 7.0, followed by adding $50 \mathrm{~g}$ of $\gamma-\mathrm{Al}_{2} \mathrm{O}_{3}$ [AOK-63-11(V grade), manufactured by the Angarsk Catalyst and Organic Synthesis Plant, Irkutsk Region, Russia] calcined at $350^{\circ} \mathrm{C}$. The resultant suspension was stirred at $70^{\circ} \mathrm{C}$ for $1 \mathrm{~h}$. During the stirring, the solution became colorless, while the $\mathrm{Al}_{2} \mathrm{O}_{3}$ pellets turned brown, indicating that $\mathrm{Pd}$ was precipitated on the support surface [15]. Next, the pellets were washed with $5 \mathrm{~L}$ of water, dried at $24^{\circ} \mathrm{C}$, and calcined at $350^{\circ} \mathrm{C}$ for $1 \mathrm{~h}$. Prior to testing, the catalyst was reduced in a hydrogen stream at $200^{\circ} \mathrm{C}$ for $2 \mathrm{~h}$. After the reduction, the catalyst turned from brown to gray, thus indicating that the supported palladium compounds were reduced.
The weight content of palladium in $\mathrm{Pd} / \mathrm{Al}_{2} \mathrm{O}_{3}$ was measured by atomic absorption spectrometry (AAS) on a Thermo iCE 3000 instrument. The analytical method has been detailed in references $[16,17]$. The AAS relative measurement error for metal content in catalysts does not exceed $10 \%$ [18].

Micrographs of supported palladium particles were obtained by transmission electron microscopy (TEM) on a JEOL JEM 2100F/UHR instrument at a resolution of $0.1 \mathrm{~nm}$. The average particle size was derived from measurements of 200-250 particles. Supported palladium particles were identified by energy dispersive X-ray spectroscopy (EDX) on a JED-2300 instrument [14].

The X-ray photoelectron spectra (XPS) of palladium were recorded on a Kratos Axis Ultra DLD spectrometer with monochromated $\mathrm{Al} K_{\alpha}$ radiation (1486.6 eV) [19]. For the recording, an electron gun was used to neutralize the static charge on catalyst pellets. The analyzer's transmission energy for recording the spectra was $40 \mathrm{eV}$ with energy steps of $0.1 \mathrm{eV}$. The energy scale was calibrated using an Au foil with an Au electron binding energy of $4 f_{7 / 2}=(83.96 \pm 0.03) \mathrm{eV}$.

The catalyst acidity was measured by ammonia temperature-programmed desorption $\left(\mathrm{NH}_{3}-\mathrm{TPD}\right)$ on a USGA-101 chemisorption analyzer. For this purpose, $0.2 \mathrm{~g}$ of a sample was placed in a quartz reactor and calcined in a He stream at a flow rate of $20 \mathrm{~mL} / \mathrm{min}$ at $400^{\circ} \mathrm{C}$ for $1 \mathrm{~h}$. The reactor was cooled to $25^{\circ} \mathrm{C}$, and the sample was saturated with ammonia vapor for $30 \mathrm{~min}$. The physically adsorbed forms of ammonia were removed by calcination in a He stream at $100^{\circ} \mathrm{C}$ for $1 \mathrm{~h}$. Then the sample was heated linearly at a rate of $8^{\circ} \mathrm{C} / \mathrm{min}$ to $750^{\circ} \mathrm{C}$ in a He stream $(30 \mathrm{~mL} / \mathrm{min})$. The ammonia evolved was recorded with a thermal conductivity detector.

The textural properties of the catalyst were measured on a NOVA 2000 instrument (Quantachrome Instruments US). Prior to the examination, the samples were degassed at $300^{\circ} \mathrm{C}$ for $2 \mathrm{~h}$, placed in the instrument, and nitrogen adsorption/desorption isotherms were recorded. The specific surface area $\left(S_{\mathrm{BET}}\right)$ was derived from the adsorption isotherms in the range of $P / P_{\mathrm{S}}=0.05-0.3$ using the Brunauer-Emmett-Teller (BET) equation. The $S_{\mathrm{BET}}$ error was $7-10 \%$. The total pore volume $\left(V_{\mathrm{S}}\right)$ was derived from the amount of adsorbed nitrogen at a relative pressure of $P / P_{\mathrm{S}}=0.99$. The micropore volume $\left(V_{\mathrm{M}}\right)$ was determined by the t-method. The $V_{\mathrm{M}}$ and $V_{\mathrm{S}}$ errors equaled 5-10\%. The differential distribution curves (DDC) of pore diameter with respect to pore volume were drawn

PETROLEUM CHEMISTRY Vol. 61 No. 42021 
using the nitrogen desorption isotherm and the BarrettJoyner-Halenda (BJH) equation. The calculation was performed using software supplied with the instrument. The main pore size $(D)$ was derived from the DDC with a $D$ error of $10-14 \%$.

The catalytic tests were performed on a Parr 5000 Series autoclave-type unit at $275^{\circ} \mathrm{C}$ (pre-selected optimum temperature) [8]. In the standard experiment setting, $30 \mathrm{~mL}$ of ethanol and $5 \mathrm{~g}$ of the catalyst were placed in the reactor. The reactor was purged with Ar, heated to $275^{\circ} \mathrm{C}$, and the mixture was stirred at $1200 \mathrm{rpm}$. After a preset time, the stirring and heating were stopped, the reactor was opened, and the gaseous and liquid HC mixtures were sampled. The reaction products were analyzed by gas chromatography (GC): specifically, $\mathrm{C}_{1}-\mathrm{C}_{4}$ gases on a Crystal-4000M chromatograph (Meta-Chrom Russia, equipped with a FID and an HP-PLOT column); and $\mathrm{CO}, \mathrm{CO}_{2}$, and $\mathrm{H}_{2}$ on a Crystal-4000 chromatograph (Meta-Chrom Russia, thermal conductivity detector, SCT grade activated carbon column). The qualitative composition of liquid organics was determined on an MSD 6973 instrument (Agilent Technologies US, FID, HP-5MS column) and on an Automass-150 instrument (Delsi Nermag France, FID, CPSil-5 column), with EI = $70 \mathrm{eV}$. The quantitative composition of liquid organics was measured on a Varian 3600 instrument (Varian US, FID, Chromatec SE-30 column, $n$-octane as an internal standard).

The ethanol conversion rate $(\alpha)$ was determined by the formula: $\alpha=\left(\mathrm{C}_{2} \mathrm{H}_{5} \mathrm{OH}\right)_{\text {prod }}\left(\mathrm{C}_{2} \mathrm{H}_{5} \mathrm{OH}\right)_{\text {init }}{ }^{-1} \times 100 \%$, where $\left(\mathrm{C}_{2} \mathrm{H}_{5} \mathrm{OH}\right)_{\text {prod }}$ refers to the amount of ethanol in the reaction product $(\mathrm{mol})$; and $\left(\mathrm{C}_{2} \mathrm{H}_{5} \mathrm{OH}\right)_{\text {init }}$ refers to the amount of initial ethanol (mol). The selectivity for the $i$ th component $\left(S_{i}\right)$ was determined by the formula: $S_{i}=$ $0.5 \operatorname{In}_{i}\left[\left(\mathrm{C}_{2} \mathrm{H}_{5} \mathrm{OH}\right)_{\text {init }}-\left(\mathrm{C}_{2} \mathrm{H}_{5} \mathrm{OH}\right)_{\text {prod }}\right]^{-1}$, where $I$ refers to the number of $\mathrm{C}$ atoms in a molecule of the $i$ th component; $n_{i}$ is the amount of the $i$ th component (mol); and $\left.\left[\left(\mathrm{C}_{2} \mathrm{H}_{5} \mathrm{OH}\right)_{\text {init }}-\left(\mathrm{C}_{2} \mathrm{H}_{5} \mathrm{OH}\right)_{\text {prod }}\right)\right]$ is the amount of reacting alcohol (mol). The yield of the $i$ th component $(\omega)$ was determined by the formula: $\omega=\alpha S / 100$.

\section{RESULTS AND DISCUSSION}

Composition of $\mathrm{Pd} / \mathrm{Al}_{2} \mathrm{O}_{3}$-catalyzed ethanol conversion products. In the first stage of the study, $30 \mathrm{~mL}$ of ethanol and a catalyst sample were placed in the reactor, and the mixture was stirred at $275^{\circ} \mathrm{C}$ for $1 \mathrm{~h}$. Then the stirring was stopped, the reactor was cooled to room temperature, and the reaction mixture was analyzed. After
Table 1. Composition of liquid organics after $1 \mathrm{~h}$ of ethanol conversion over $\mathrm{Pd} / \mathrm{Al}_{2} \mathrm{O}_{3}$

\begin{tabular}{l|c}
\hline $\mathrm{C}_{x} \mathrm{H}_{y} \mathrm{O}_{z}$ components & wt \% (GLC) \\
\hline$\sum\left(\mathrm{C}_{x} \mathrm{H}_{\mathrm{y}} \mathrm{O}_{\mathrm{z}}\right)$ & $0.04 \mathrm{~mol}$ \\
$n$-Butanol & 72.63 \\
Ethoxyethane & 8.62 \\
$n$-Hexanol & 6.88 \\
Ethanol & 0.22 \\
Butane & 2.17 \\
But-1-ene & 2.61 \\
But-2-en-1-ol & 0.87 \\
Butanal & 0.43 \\
Butan-2-ol & 0.36 \\
Ethyl acetate & 1.16 \\
1-Ethoxybutane & 0.94 \\
1,2-Diethoxyethane & 0.29 \\
Butyl acetate & 0.07 \\
Ethoxyhexane & 0.07 \\
Other $\mathrm{C}_{8+}$ & 2.68 \\
\hline
\end{tabular}

$1 \mathrm{~h}$, the mixture in the reactor consisted of water $(0.65 \mathrm{~mL}$, $0.036 \mathrm{~mol})$, liquid $\mathrm{HCs}(29 \mathrm{~mL}, 0.48 \mathrm{~mol})$, and gaseous HCs $(72 \mathrm{~mL}, 0.003 \mathrm{~mol})$. This composition indicates that catalytic conversion of ethanol occurred in the reactor. The total content of components in the reactor measured after $1 \mathrm{~h}$ of the reaction was $99.5 \pm 0.6 \%$ relative to the amount of initial ethanol, indicating no loss during the catalysis.

The GC composition of the liquid organics is presented in Table 1.

The main product of the mixture is butanol, the content of which after $1 \mathrm{~h}$ of the reaction was $72.63 \%$. The liquid product was found to contain trace amounts $(0.22-0.87 \%)$ of ethanal, but-2-en-1-ol, and butanal. These compounds are typical intermediates in ethanol conversion to butanol occurring by mechanism II [4-6]. Therefore, it is reasonable to assume that, under our test conditions, ethanol is converted by mechanism II [Fig. 2, reactions (1)-(5)].

Apart from butanol, the liquid product contains hexanol (6.88\%) and ethoxyethane (8.62\%). Hexanol is most likely formed from the condensation of butanol and ethanol on $\mathrm{Pd} / \mathrm{Al}_{2} \mathrm{O}_{3}$ active sites [Fig. 2, reaction (6)]. Ethoxyethane is produced from ethanol dehydration on $\mathrm{Al}_{2} \mathrm{O}_{3}$ acid sites [Fig. 2, reaction (7)]. 
Table 2. Composition of gaseous product after $1 \mathrm{~h}$ of ethanol conversion over $\mathrm{Pd} / \mathrm{Al}_{2} \mathrm{O}_{3}$

\begin{tabular}{l|c}
\hline $\mathrm{C}_{x} \mathrm{H}_{y} \mathrm{O}_{z}$ components & wt \% (GLC) \\
\hline$\sum\left(\mathrm{C}_{x} \mathrm{H}_{y} \mathrm{O}_{z}\right)$ & $0.003 \mathrm{~mol}$ \\
$\mathrm{H}_{2}$ & 33.06 \\
$\mathrm{CO}_{2}$ & 28.12 \\
Methane & 27.02 \\
Ethane & 3.11 \\
Ethene & 0.56 \\
Propane & 6.22 \\
Propene & 0.52 \\
Butane & 0.33 \\
But-1-ene & 0.36 \\
CO & 0.70 \\
\hline
\end{tabular}

Minor amounts of but-1-ene, butane, ethyl acetate, butyl acetate, ethoxybutane, butan-2-ol, ethoxyhexane, 1,2-diethoxyethane, and $\mathrm{C}_{8+}$ aliphatic hydrocarbons with various structures were also detected in the mixture (Table 1).
The amount of the gaseous reaction product is $0.003 \mathrm{~mol}$, which is about an order of magnitude lower than the liquid organic product $(0.04 \mathrm{~mol})$. The gases mostly consist of hydrogen, methane, and $\mathrm{CO}_{2}$ (Table 2). They also contain minor amounts of $\mathrm{C}_{2}-\mathrm{C}_{4}$ hydrocarbons and $\mathrm{CO}$. Probable reactions forming the above-listed components are illustrated in Fig. 2.

The above data suggest that, after $1 \mathrm{~h}$ of the reaction, the main products of ethanol conversion are butanol, hexanol, and ethoxyethane. Analysis of reaction mixtures in longer-term experiments leads to the same conclusion. In order to gain insight into the accumulation of the main products and the consumption of ethanol over time, we investigated the kinetics of ethanol conversion during $5 \mathrm{~h}$ of continuous service of the catalyst. The relevant data are provided in the next section.

Kinetic regularities of $\mathrm{Pd} / \mathrm{Al}_{2} \mathrm{O}_{3}$-catalyzed ethanol conversion. Figure 3 shows a gradual decline in ethanol concentration from 17.3 to $13 \mathrm{~mol} / \mathrm{L}$ at $275^{\circ} \mathrm{C}$ within a time interval of $0-5 \mathrm{~h}$. This trend indicates that ethanol conversion occurs over the entire interval. Between

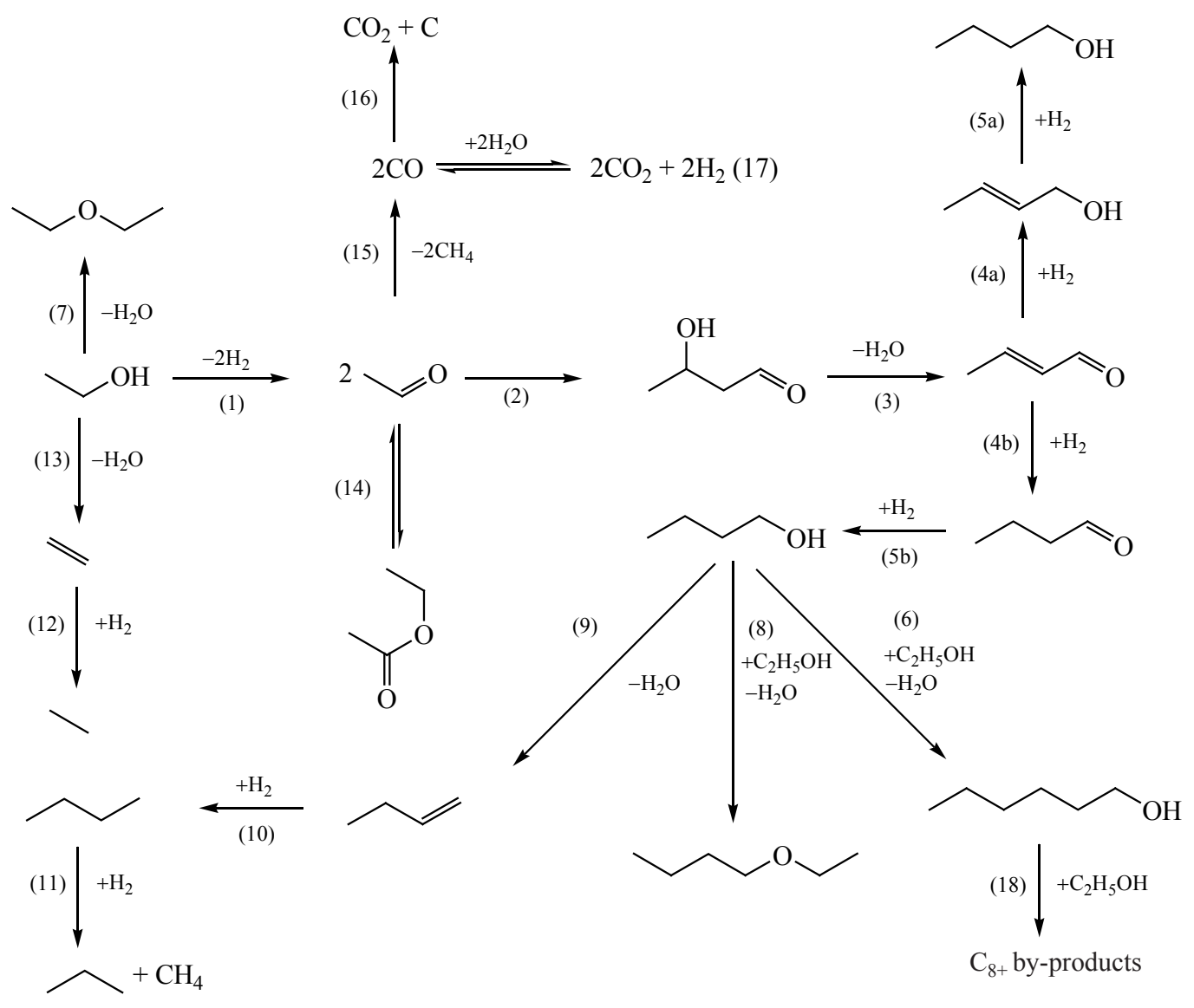

Fig. 2. Ethanol conversion over $\mathrm{Pd} / \mathrm{Al}_{2} \mathrm{O}_{3}$ (reaction routes based on the data of Tables 1 and 2). 


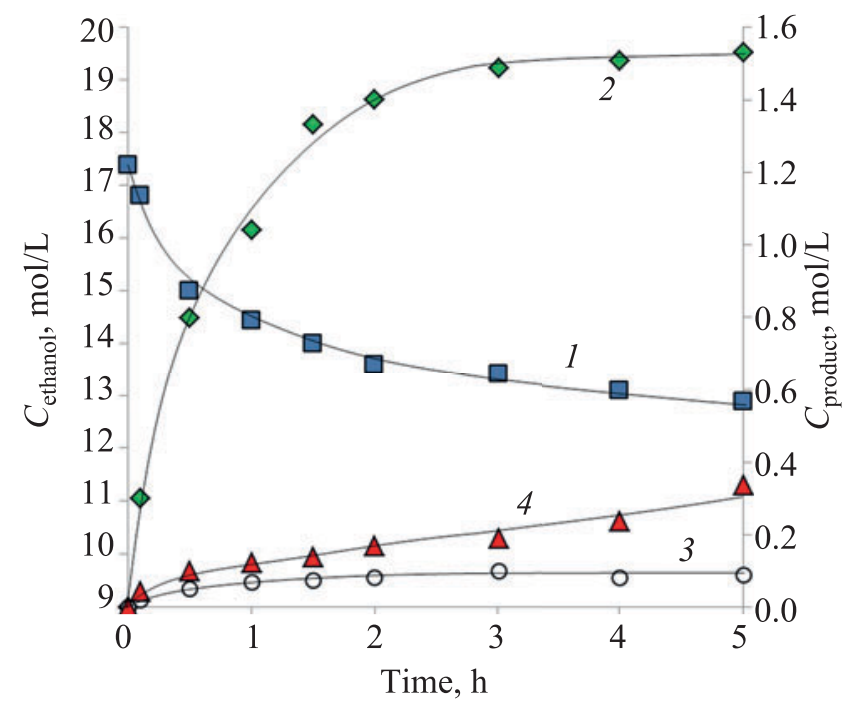

Fig. 3. Kinetic curves of ethanol consumption and of accumulation of main ethanol (1) conversion products: (2) butanol, (3) hexanol, (4) ethoxyethane. Reaction conditions: $V\left(\mathrm{C}_{2} \mathrm{H}_{5} \mathrm{OH}\right)=30 \mathrm{~mL} ; m\left(\mathrm{Pd} / \mathrm{Al}_{2} \mathrm{O}_{3}\right)=5 \mathrm{~g} ; T=$ $275^{\circ} \mathrm{C}$.

0 and $0.5 \mathrm{~h}$, the accumulation kinetic curves of the main products are satisfactorily linearized, thus making it possible to evaluate the initial reaction rates. Based on the experimental data, the initial formation rates for the following substrates were derived: butanol (1.6 $\left.\mathrm{mol} \mathrm{L}^{-1} \mathrm{~h}^{-1}\right)$, ethoxyethane $\left(0.2 \mathrm{~mol} \mathrm{~L}^{-1} \mathrm{~h}^{-1}\right)$, and hexanol $\left(0.1 \mathrm{~mol} \mathrm{~L}^{-1} \mathrm{~h}^{-1}\right)$.

Butanol accumulation starts slowing down within 0.5-3 h, and almost ceases between $3 \mathrm{~h}$ and $5 \mathrm{~h}$ (Fig. 3). The butanol formation rate within $3-5 \mathrm{~h}$ was evaluated as $0.02 \mathrm{~mol} \mathrm{~L}^{-1} \mathrm{~h}^{-1}$, which is about a factor of 80 lower than the initial butanol formation rate. The time variation in the hexanol concentration is described by a similar functional relationship: substrate accumulation within 0.5-3 h, followed by an abrupt deceleration (Fig. 3).

These kinetics of butanol and hexanol formation can be explained by assumed deactivation of metal sites and/or acid sites of the $\mathrm{Pd}^{0}-\mathrm{Al}_{2} \mathrm{O}_{3}$ catalyst, which are required to ensure conversion of ethanol to the abovementioned alcohols [Fig. 2, reactions (1)-(5) and (5)-(6)]. In contrast to butanol and hexanol, the ethoxyethane accumulation curve demonstrates an increase in the substrate concentration throughout the entire time interval of $0-5 \mathrm{~h}$. This can be explained by an assumption that the $\mathrm{Al}_{2} \mathrm{O}_{3}$ acid sites required for ethanol conversion to ethoxyethane undergo no significant changes during the

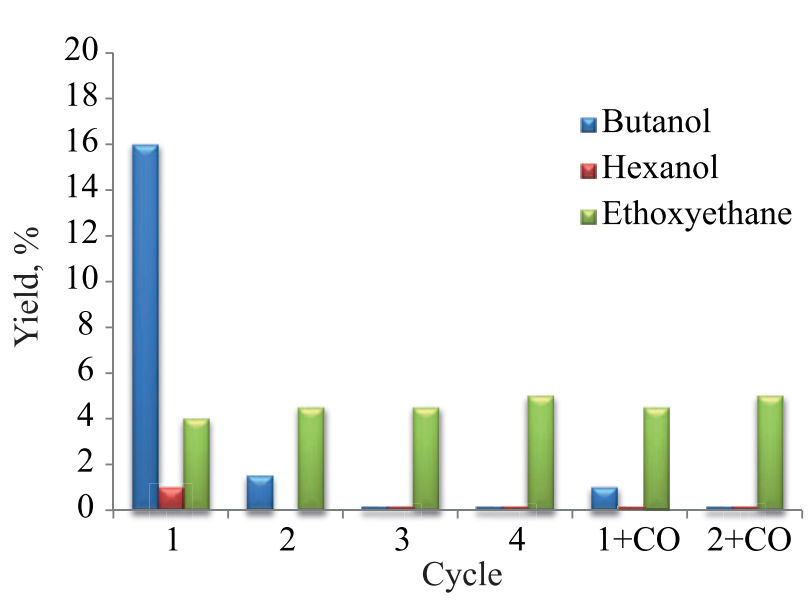

Fig. 4. Product yields in four test cycles of one catalyst sample [Cycle conditions: $V\left(\mathrm{C}_{2} \mathrm{H}_{5} \mathrm{OH}\right)=30 \mathrm{~mL} ; m\left(\mathrm{Pd} / \mathrm{Al}_{2} \mathrm{O}_{3}\right)=5 \mathrm{~g}$; $T=275^{\circ} \mathrm{C} ; \tau=5 \mathrm{~h}$; and product yields in two test cycles of one catalyst sample with carbon monoxide added [Cycle conditions: $V\left(\mathrm{C}_{2} \mathrm{H}_{5} \mathrm{OH}\right)=30 \mathrm{~mL} ; m\left(\mathrm{Pd} / \mathrm{Al}_{2} \mathrm{O}_{3}\right)=5 \mathrm{~h} ; T=$ $\left.275^{\circ} \mathrm{C} ; \tau=5 \mathrm{~h} ; v(\mathrm{CO})=1 \times 10^{-4} \mathrm{~mol}\right]$.

catalysis [Fig. 2, reaction (7)]. As a result, ether formation is not inhibited over time.

The accumulation kinetic curves of the main ethanol conversion products (Fig. 3) are consistent with the data of consecutive test cycles for the same catalyst sample (Fig. 4).

In Cycle 1 of the $\mathrm{Pd} / \mathrm{Al}_{2} \mathrm{O}_{3}$ test, the yields of butanol, hexanol, and ethoxyethane after $5 \mathrm{~h}$ of the catalyst service are 16, 0.88, and $3.92 \%$, respectively. In Cycle 2, the yields of butanol and hexanol decrease by two orders of magnitude, while the yield of ethoxyethane remains unchanged. In Cycle 3, the ethoxyethane yield is about the same as in the previous two cycles, while the yields of butanol and hexanol have already dropped by three orders of magnitude. In Cycle 4, the catalyst activity in the synthesis of butanol and hexanol ceases to change, remaining at about $0.1 \%$ of the initial catalyst activity in the ethanol conversion to butanol and hexanol.

The above data suggest that by the end of four (4) consecutive test cycles, the $\mathrm{Pd} / \mathrm{Al}_{2} \mathrm{O}_{3}$ sample has completely lost its activity in the ethanol conversion to butanol (target product). To find the true cause(s) of $\mathrm{Pd} / \mathrm{Al}_{2} \mathrm{O}_{3}$ deactivation, the structures of the original catalyst vs. the spent catalyst after Cycle 4 were examined. Probable deactivation models were then tested. 

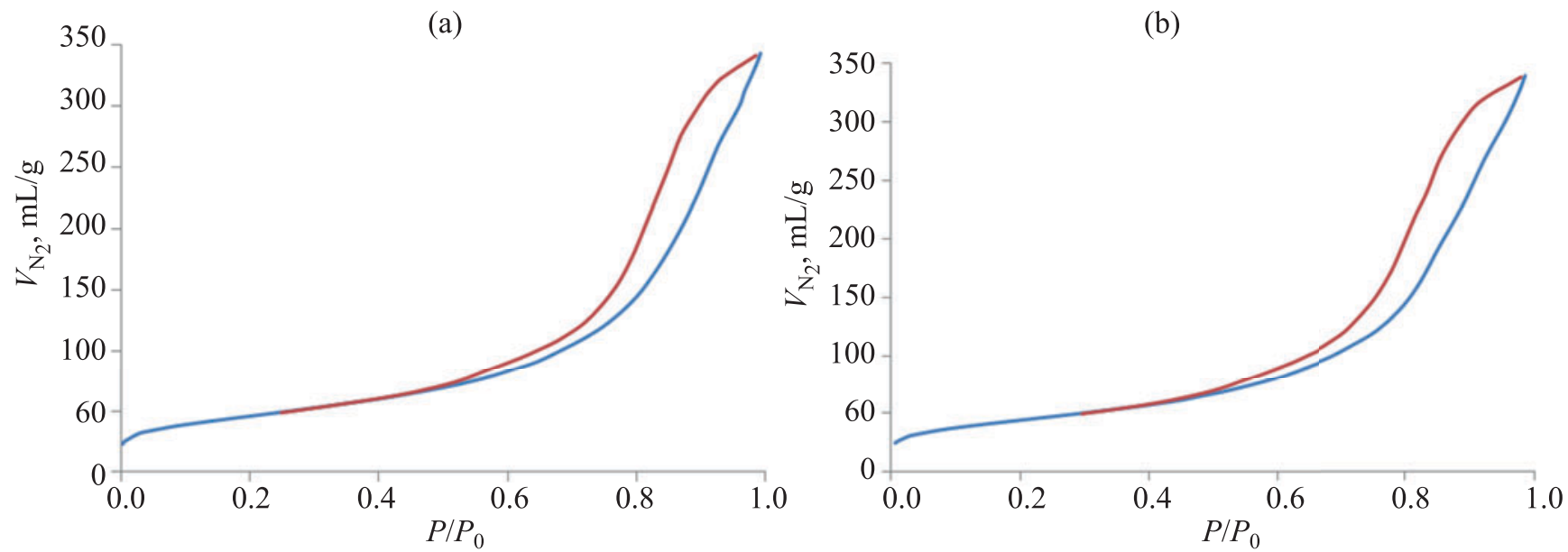

Fig. 5. $\mathrm{N}_{2}$ adsorption/desorption isotherms: (a) initial catalyst; and (b) catalyst after Cycle 4.

Probable causes of deactivation of supported palladium catalyst. Deactivation due to changes in $\mathrm{Pd} / \mathrm{Al}_{2} \mathrm{O}_{3}$ porous structure. Under vigorous stirring (1200 rpm), the $\mathrm{Pd} / \mathrm{Al}_{2} \mathrm{O}_{3}$ pellets rub together and against the reactor walls. Over time, the mechanical friction can affect the internal catalyst structure and, in particular, narrow the pores [20]. Because the pore size is crucial for the rate of substrate diffusion to and from the active sites [3], narrower pores make the diffusion more energyconsuming, thus slowing down the catalytic reaction. In an extreme case, the narrowing of pores may encapsulate the loaded metal within the bulk of the support, with complete blockage of access to the support for the reaction substrates.

If the deactivation model based on changes in the $\mathrm{Pd} / \mathrm{Al}_{2} \mathrm{O}_{3}$ porous structure is correct, the following parameters of the initial and spent catalyst must differ significantly: specific surface area, pore size, and total pore volume. These properties were measured by lowtemperature nitrogen adsorption. The $\mathrm{N}_{2}$ adsorption/ desorption isotherms, both for the initial and spent catalyst, are provided in Fig. 5.
Both samples are characterized by IUPAC type IV isotherms [21]. These isotherms contain a capillarycondensation hysteresis loop, indicating the porous structure of the materials examined. The hysteresis loops of both samples have a shape close to de Boer's type A, typical of materials with cylindrical pores. In general, the $\mathrm{N}_{2}$ adsorption/desorption for the initial and spent samples differ only slightly (Fig. 5). The data derived from the respective isotherms are presented in Table 3.

Table 3 shows that, for the initial catalyst, the specific surface area $\left(S_{\mathrm{BET}}\right)$ is $162 \mathrm{~m}^{2} / \mathrm{g}$, the predominant pore type is a $3-10 \mathrm{~nm}$ mesopore, the total pore volume $\left(V_{\mathrm{S}}\right)$ is $0.525 \mathrm{~mL}^{3} / \mathrm{g}$, and the micropore volume $\left(V_{\mathrm{M}}\right)$ is $0.001 \mathrm{~mL}^{3} / \mathrm{g}$. The spent catalyst, within the margin of error, is characterized by the same pore size and the same values of $S_{\mathrm{BET}}, V_{\mathrm{S}}$, and $V_{\mathrm{M}}$ (Table 3 ).

These data lead to a conclusion that the porous structure of the catalyst is not affected noticeably in the course of the catalysis. For this reason, the deactivation model discussed in this section does not fit our test conditions.

Table 3. Structural properties of initial and spent (after Cycle 4) catalysts ${ }^{\mathrm{a}}$

\begin{tabular}{|c|c|c|c|c|c|c|c|c|c|}
\hline Catalyst sample & $\begin{array}{l}S_{\mathrm{BET}}, \\
\mathrm{m}^{2} / \mathrm{g}\end{array}$ & $D, \mathrm{~nm}$ & $V_{\mathrm{S}}, \mathrm{mL}^{3 / \mathrm{g}}$ & $\begin{array}{c}V_{\mathrm{M}}, \\
\mathrm{mL}^{3} / \mathrm{g}\end{array}$ & $\begin{array}{c}{[\mathrm{AS}],} \\
\mu \mathrm{mol} / \mathrm{g}\end{array}$ & $\begin{array}{c}{[\mathrm{Pd}]_{\mathrm{V}}, \mathrm{wt}} \\
\%\end{array}$ & $\underset{\%}{[\mathrm{Pd}]_{\mathrm{S}}, \text { at }}$ & $D_{\mathrm{Pd}}, \mathrm{nm}$ & $\begin{array}{c}\mathrm{Pd} 3 d_{5 / 2}, \\
\mathrm{eV}\end{array}$ \\
\hline & 162 & $3-10$ & 0.525 & 0.001 & 230 & 0.09 & 0.1 & 9 & 335.1 \\
\hline Spent & 160 & $3-10$ & 0.534 & 0.001 & 232 & 0.1 & 0.1 & 9 & 335.1 \\
\hline
\end{tabular}

${ }^{a} S_{\mathrm{BET}}$ is the BET specific surface area; $D$ is the predominant pore size; $V_{\mathrm{S}}$ is the $\mathrm{N}_{2}$-based total pore volume; $V_{\mathrm{M}}$ is the micropore volume; [AS] is the $\mathrm{NH}_{3}$-based relative acidity; $[\mathrm{Pd}]_{\mathrm{V}}$ is the metal content in catalyst bulk; $[\mathrm{Pd}]_{\mathrm{S}}$ is the metal content on catalyst surface; $D_{\mathrm{Pd}}$ is the average size of Pd particles; and $\mathrm{Pd} 3 d_{5 / 2}$ is the electron binding energy. 
Deactivation due to blockage of $\mathrm{Al}_{2} \mathrm{O}_{3}$ acid sites. An interaction of $\mathrm{Al}_{2} \mathrm{O}_{3}$ with oxygen-containing intermediates of ethanol conversion (Fig. 2) may form stable $\mathrm{Al}^{3+} \ldots \mathrm{O}-\mathrm{RH}$ type complexes [20, 22, 23]. Over time, the content of such complexes on the catalyst surface may exceed the concentration of $\mathrm{Al}^{+3}$ Lewis acid sites involved in the aldol condensation and dehydration steps of the ethanol-to-butanol synthesis chain [Fig. 2, reactions (2) and (3)]. In this case, obviously, the entire target reaction route will be retarded.

If the deactivation model based on blockage of $\mathrm{Al}_{2} \mathrm{O}_{3}$ active sites is correct, the acidity values of the initial and spent catalysts must differ. The acidity was measured by $\mathrm{NH}_{3}-\mathrm{TPD}$. The $\mathrm{NH}_{3}-\mathrm{TPD}$ profiles of the initial and spent samples are shown in Fig. 6.

The similarity of the profile shapes points to a similarity in the qualitative compositions of $\mathrm{Al}_{2} \mathrm{O}_{3}$ active sites both in the initial and the spent catalyst. The calculated integral acidity of the initial sample is $230 \mu \mathrm{mol} / \mathrm{g}$, and the spent sample has an acidity of $232 \mu \mathrm{mol} / \mathrm{g}$ (Table 3). We can conclude that both samples have, within the margin of error, the same acidity. Consequently, the $\mathrm{Pd} / \mathrm{Al}_{2} \mathrm{O}_{3}$ deactivation model discussed in this section does not fit our test conditions.

Deactivation due to $\mathrm{Pd}$ removal from $\mathrm{Pd} / \mathrm{Al}_{2} \mathrm{O}_{3}$ surface. An interaction of the palladium phases with the organic products of ethanol conversion (Fig. 2) may form soluble Pd compounds (colloidal Pd particles) followed by a transfer of the Pd phases from the catalyst into the bulk of the reactor. Such cases are described in references $[22,23]$. Leaching of $\mathrm{Pd}$ from $\mathrm{Pd} / \mathrm{Al}_{2} \mathrm{O}_{3}$ will clearly reduce the number of sites required to catalyze ethanol

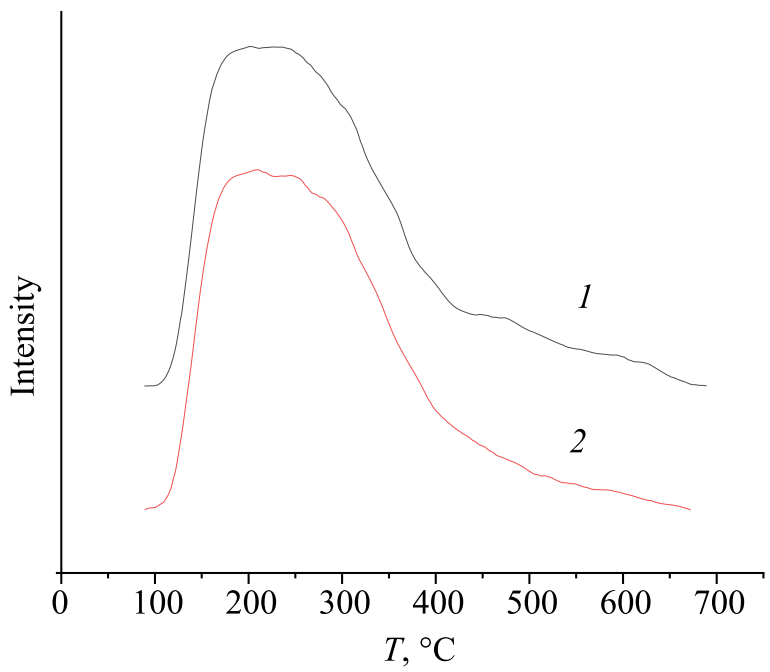

Fig. 6. $\mathrm{NH}_{3}-\mathrm{TPD}$ profiles of (1) initial catalyst and (2) spent catalyst.

dehydrogenation [Fig. 2, reaction (1)]. Accordingly, this will slow down the ethanol conversion to butanol.

If the deactivation model based on Pd removal from the catalyst is correct, the weight content and surface content of Pd must differ for the initial catalyst compared to the spent catalyst. To evaluate these parameters, the metal concentration in a catalyst sample solution with the predefined weight was measured by AAS (Fig. 7), and the metal concentration on the catalyst pellet surface was calculated from the XPS panoramic spectra (Fig. 7).

The resultant concentrations are presented in Table 3. The initial and spent catalysts contain the same amounts of palladium, both in terms of bulk and surface content (Table 3). Therefore, the $\mathrm{Pd} / \mathrm{Al}_{2} \mathrm{O}_{3}$ deactivation model discussed in this section does not fit our test conditions.
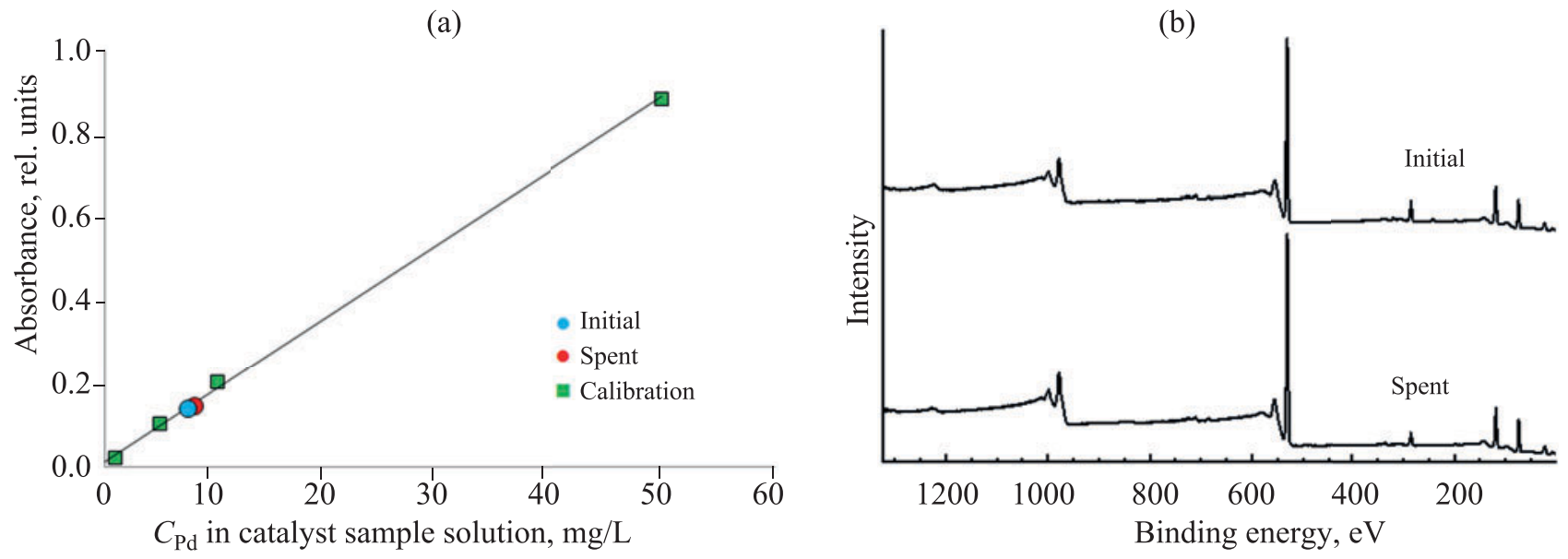

Fig. 7. (a) AAS calibration line with experimental Pd concentrations; and (b) XPS panoramic spectra of catalyst surface. 


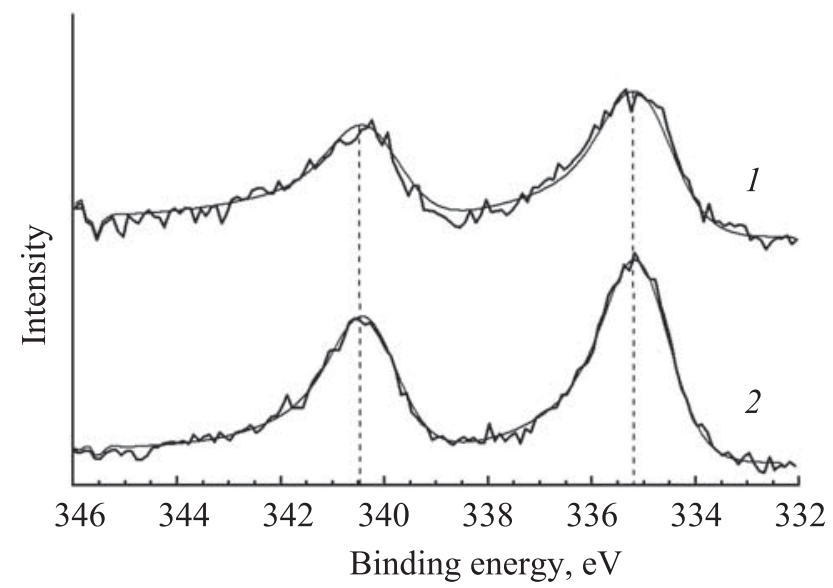

Fig. 8. XPS spectra of Pd $3 d$ for (1) initial and (2) spent catalysts.

Deactivation due to changes in Pd oxidation degree. Reduced palladium phases have been known to be the most active in dehydrogenation and hydrogenation reactions $[15,24,25]$. Oxidation of the catalyst sample's palladium (e.g., due to oxygen adsorbed in the support pores) may slow down both the ethanol dehydrogenation [Fig. 2, reaction (1)] and the hydrogenation of target intermediates [Fig. 2, reactions (4) and (5)]. As a result, ethanol conversion to butanol will also be inhibited.

If the deactivation model based on changes in palladium's electronic structure is correct, the X-ray photoelectron spectra of the $\mathrm{Pd} 3 d$ core electron levels of the initial and spent samples must differ $[14,26]$. These XPS spectra are provided in Fig. 8.

The XPS spectra clearly contain a doublet peak $\left(\operatorname{Pd} 3 d_{5 / 2}\right.$ and $\left.\mathrm{Pd} 3 d_{3 / 2}\right)$, typical of palladium, with a spin-orbit splitting of $5.3 \mathrm{eV}$. The asymmetric shape is typical of the $\mathrm{Pd} 3 d$ zero-valent metal peaks. The $\operatorname{Pd} 3 d_{5 / 2}$ electron binding energy in the spectrum of the initial and spent catalyst is $335.3 \pm 0.1 \mathrm{eV}$ (Fig. 8). The binding energy obtained is typical of metal palladium phases supported on alumina $[14,26]$. Therefore, the $\mathrm{Pd} / \mathrm{Al}_{2} \mathrm{O}_{3}$ deactivation model discussed in this section does not fit our test conditions.

Deactivation due to sintering of Pd phases. The catalyst heating may lead to the aggregation of the supported palladium phases, thus decreasing the number of $\mathrm{Pd}$ active sites in the bulk of the reactor [22, 23]. If the deactivation model based on the aggregation of supported palladium phases in $\mathrm{Pd} / \mathrm{Al}_{2} \mathrm{O}_{3}$ is correct, the palladium particle size histograms and the average particle size must
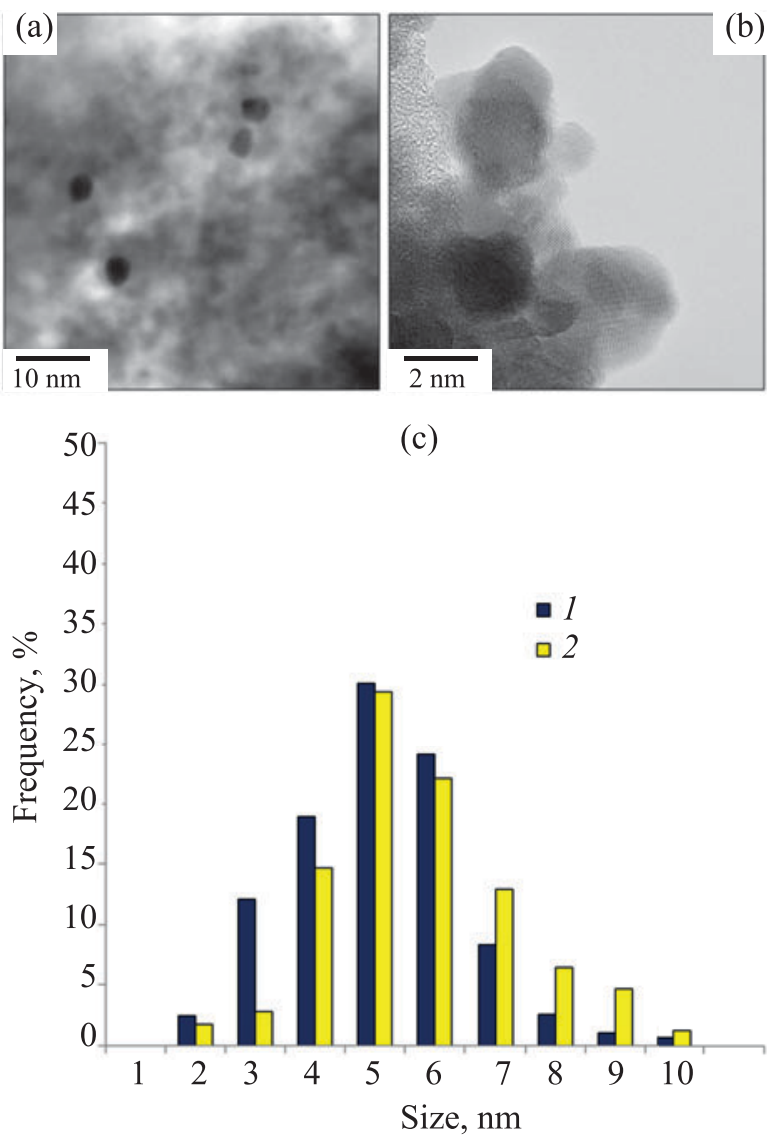

Fig. 9. (a, b) TEM micrographs of $\mathrm{Pd} / \mathrm{Al}_{2} \mathrm{O}_{3}$ demonstrating Pd particles in initial sample; (c) Pd particle size histogram for (1) initial vs. (2) spent catalyst.

differ between the initial sample and the spent sample. These parameters were measured by TEM.

The typical micrographs of Pd particles and the histograms of particle size distribution are provided in Fig. 9. These clearly show that the palladium phases appear as dark rounded particles that contrast well with the gray background of the support. The initial sample contains $2 \mathrm{~nm}$ to $18 \mathrm{~nm}$ particles. The average size of the Pd particles is $9 \pm 2 \mathrm{~nm}$. The particle size histogram for the spent sample contains particle fractions $2-$ $18 \mathrm{~nm}$ in size. The average Pd particle size in the spent sample is $9 \pm 2 \mathrm{~nm}$. These data suggest that the $\mathrm{Pd} / \mathrm{Al}_{2} \mathrm{O}_{3}$ deactivation model discussed in this section does not fit our test conditions.

Deactivation due to Pd phase interaction with carbon monoxide. References $[9,10]$ note low stability of $\mathrm{Ni}$ catalysts serving for ethanol conversion to butanol. Moreover, coke precursors (i.e., $\mathrm{C}_{2} \mathrm{H}_{2}, \mathrm{CH}_{4}$, and $\mathrm{CO}$ ) were detected in the products of $\mathrm{Ni}$-catalyzed conversion. 
These studies concluded that the catalyst is deactivated due to coke adsorption on the Ni phases. We also found it relevant to test a similar deactivation model because the gaseous portion of the ethanol conversion product obtained over $\mathrm{Pd} / \mathrm{Al}_{2} \mathrm{O}_{3}$ contained both $\mathrm{CH}_{4}$ and $\mathrm{CO}$ (Table 1) in amounts comparable to the amount of palladium in the catalyst sample.

The following coking reactions are known: $\mathrm{CH}_{4} \rightarrow \mathrm{C}+2 \mathrm{H}_{2}$ and $2 \mathrm{CO} \rightarrow \mathrm{CO}_{2}+\mathrm{C}[4,27] . \mathrm{CH}_{4}$-to-C conversion occurs at $600-800^{\circ} \mathrm{C}$, which far exceeds the temperature imposed in our catalytic test $\left(275^{\circ} \mathrm{C}\right)$. Therefore, this coking route can almost certainly be disregarded. In contrast to methane, $\mathrm{CO}$ is converted to $\mathrm{C}$ at $245^{\circ} \mathrm{C}$ [27], which makes $\mathrm{CO}$ the most likely coke precursor in our case [Fig. 2, reaction (16)]. It is also worth noting that at $275^{\circ} \mathrm{C}$, even despite the relatively low rate of $\mathrm{CO}$ conversion, $\mathrm{CO}$ molecules still have to be considered as a potential poison that will block Pd active sites due to the formation of strong $\mathrm{Pd}-\mathrm{CO}$ complexes $[28,29]$.

Given the small metal content in the catalyst sample $\left(4.7 \times 10^{-5} \mathrm{~mol}\right)$, even trace coke deposits can significantly limit the activity of $\mathrm{Pd} / \mathrm{Al}_{2} \mathrm{O}_{3}$ and lead to its deactivation. It is too difficult to reliably measure the growth in minute quantities of carbon phases on the catalyst (especially after its involvement in the conversion of organic intermediates). The same challenge arises in a quantitative analysis of adsorbed $\mathrm{CO}$ molecules. This is why, in this study, we used pre-poisoning when testing the $\mathrm{Pd} / \mathrm{Al}_{2} \mathrm{O}_{3}$ deactivation model based on coking and/or $\mathrm{CO}$ adsorption on $\mathrm{Pd}$ active sites.

The testing procedure was essentially as follows. $1 \times 10^{-4}$ mol of CO (an amount comparable to the total content of palladium in the $\mathrm{Pd} / \mathrm{Al}_{2} \mathrm{O}_{3}$ sample) was added into the autoclave where the ethanol and the initial $\mathrm{Pd} / \mathrm{Al}_{2} \mathrm{O}_{3}$ had been placed. Then two testing cycles were run, and the product composition was analyzed. Figure 4 indicates that even in Cycle 1 the product yield over the pre-poisoned catalyst is 16 times lower than in the case of ethanol conversion with the initial Pd catalyst. In Cycle 2, the pre-poisoned Pd catalyst completely loses its activity. Thus, carbon monoxide evolved during the target reaction [Fig. 2, reaction (15)] can be considered as the main cause of Pd catalyst deactivation.

\section{CONCLUSIONS}

A Pd/ $\mathrm{Al}_{2} \mathrm{O}_{3}$ catalyst $(\mathrm{Pd}=0.1 \mathrm{wt} \%)$ was observed to exhibit high initial activity in ethanol conversion to butanol at $275^{\circ} \mathrm{C}$. However, the $\mathrm{Pd} / \mathrm{Al}_{2} \mathrm{O}_{3}$ lost more than $99 \%$ of its initial activity after $10 \mathrm{~h}$ of service. Based on structural examinations, probable deactivation mechanisms were explored, including: poisoning due to adsorption of $\mathrm{CO}$ molecules on the catalyst; sintering of Pd phases upon heating; leaching of $\mathrm{Pd}$ phases from catalyst pellets; changes in the electronic state of Pd active sites; changes in the catalyst's porous structure; and blockage of $\mathrm{Al}_{2} \mathrm{O}_{3}$ active sites. The deactivation was found to be mainly caused by $\mathrm{CO}$ molecules evolved during the side decarbonylation process. These molecules can either block $\mathrm{Pd}$ active sites due to the formation of strong $\mathrm{Pd}-\mathrm{CO}$ complexes, or enter a $\mathrm{CO}$ disproportionation reaction to form carbon deposits on the Pd phases.

The knowledge gained from this study can be used for developing $\mathrm{Pd}$ catalysts with high performance stability. For example, the $\mathrm{CO}$ adsorption can be suppressed by utilization of a ligand effect in bimetallic $\mathrm{Pd}-\mathrm{M}$ systems (where $\mathrm{M}=\mathrm{Fe}, \mathrm{Ni}, \mathrm{Co}, \mathrm{Zn}, \mathrm{Cu}$ ). Metals (M) have been known to act as a modifier of the $\mathrm{Pd}$ electronic structure, as they shift the Pd d-zone center downward from the Fermi level [30,31], thus decreasing the $\mathrm{CO}-\mathrm{Pd}$ binding energy. Thus, $\mathrm{Pd}$-based systems, such as $\mathrm{Pd}-\mathrm{Fe} / \mathrm{Al}_{2} \mathrm{O}_{3}, \mathrm{Pd}-\mathrm{Co} / \mathrm{Al}_{2} \mathrm{O}_{3}, \mathrm{Pd}-\mathrm{Ni} / \mathrm{Al}_{2} \mathrm{O}_{3}$, $\mathrm{Pd}-\mathrm{Cu} / \mathrm{Al}_{2} \mathrm{O}_{3}, \mathrm{Pd}-\mathrm{Zn} / \mathrm{Al}_{2} \mathrm{O}_{3}$, and $\mathrm{Pd}-\mathrm{Ce} / \mathrm{Al}_{2} \mathrm{O}_{3}$, are supposed to be highly resistant to $\mathrm{CO}$ poisoning and to show stable and high activity in ethanol conversion to butanol. An alternative approach to the creation of stable catalysts could be the utilization of less dispersed Pd phases, because larger particles lead to a decrease in the CO-Pd binding energy [30]. These and other approaches to the creation of highly selective and stable ethanol conversion catalysts will be explored in our further research efforts.

\section{AUTHOR CONTRIBUTION}

D.I. Ezzhelenko: AAS and low-temperature $\mathrm{N}_{2}$ adsorption examinations, discussion of results, and graphic preparation.

S.A. Nikolaev: conceptual development, TEM and XPS examinations, discussion of results, and text preparation.

A.V. Chistyakov: catalytic testing, GLC and GC-MS analysis, and discussion of results.

P.A. Chistyakova: $\mathrm{NH}_{3}-\mathrm{TPD}$ examination and discussion of results.

M.V. Tsodikov: discussion of results and text preparation.

\section{AUTHOR INFORMATION}

D.I. Ezzhelenko, ORCID: http://orcid.org/0000-00032218-8254 

3537

S.A. Nikolaev, ORCID: http://orcid.org/0000-0002-9091-

A.V. Chistyakov, ORCID: http://orcid.org/0000-00024443-7998

P.A. Chistyakova, ORCID: http://orcid.org/0000-00023251-7181 2945

M.V. Tsodikov, ORCID: http://orcid.org/0000-0002-8253-

\section{ACKNOWLEDGMENTS}

The authors are grateful to the researchers of the "Nanochemistry and nanomaterials" Center for Collective Use in the Lomonosov Moscow State University (MSU), and in particular to K.I. Maslakov, S.V. Maksimov, and S.V. Dvoryak, for their kind cooperation in the examination of samples using equipment acquired under the MSU Development Program.

\section{FUNDING}

The study described here was performed with financial support from the Russian Foundation for Basic Research (research project no. 20-33-90011).

\section{CONFLICT OF INTEREST}

The authors declare no conflict of interest requiring disclosure in this article.

\section{OPEN ACCESS}

This article is licensed under a Creative Commons Attribution 4.0 International License, which permits use, sharing, adaptation, distribution and reproduction in any medium or format, as long as you give appropriate credit to the original author(s) and the source, provide a link to the Creative Commons licence, and indicate if changes were made. The images or other third party material in this article are included in the article's Creative Commons licence, unless indicated otherwise in a credit line to the material. If material is not included in the article's Creative Commons licence and your intended use is not permitted by statutory regulation or exceeds the permitted use, you will need to obtain permission directly from the copyright holder. To view a copy of this licence, visit http://creativecommons.org/licenses/by/4.0/.

\section{REFERENCES}

1. Dagle, R.A., Winkelman, A.D., Ramasamy, K.K., Dagle, V.L., and Weber, R.S., Ind. Eng. Chem. Res., 2020, vol. 59 , no. 11 , pp. $4843-4853$. https://doi.org/10.1021/acs.iecr.9b05729

2. Sun, J. and Wang, Y., ACS Catal., 2014, vol. 4, no. 4, pp. 1078-1090. https://doi.org/10.1021/cs4011343

3. Crabbe, E., Nolasco-Hipolito, C., Kobayashi, G., Sonomoto, K., and Ishizaki, A., Process Biochem., 2001, vol. 37 , no. 1, pp. 65-71.
https://doi.org/10.1016/S0032-9592(01)00178-9

4. Gabriëls, D., Hernández, W.Y., Sels, B., Voort, P.V.D., and Verberckmoes, A., Catal. Sci. Technol., 2015, vol. 5, pp. 3876-3902. https://doi.org/10.1039/C5CY00359H

5. Kozlowski, J.T. and Davis, R.J., ACS Catal., 2013, vol. 3, no. 7, pp. 1588-1600. https://doi.org/10.1021/cs400292f

6. Riittonen, T., Toukoniitty, E., Madnani, D.K., Leino, A.-R., Kordas, K., Szabo, M., Sapi, A., Arve, K., Wärnå, J., and Mikkola, J.-P., Catalysts, 2012, vol. 2, pp. 68-84. https://doi.org/10.3390/catal2010068

7. Marcu, I.-C., Tanchoux, N., Fajula, F., and Tichit, D., Catal. Lett., 2013, vol. 143, pp. 23-30. https://doi.org/10.1007/s10562-012-0935-9

8. Nikolaev, S.A., Tsodikov, M.V., Chistyakov, A.V., Zharova, P.A., and Ezzgelenko, D.I., J. Catal., 2019, vol. 369, pp. 501-517. https://doi.org/10.1016/j.jcat.2018.11.017

9. Jiang, D., Wu, X., Mao, J., Ni, J., and Li, X., Chem. Commun., 2016, vol. 52, pp. 13749-13752. https://doi.org/10.1039/C6CC05860D

10. Sun, Z., Vasconcelos, A.C., Bottari, G., Stuart, M.C.A., Bonura, G., Cannilla, C., Frusteri, F., and Barta, K., ACS Sustain. Chem. Eng., 2017, vol. 5, no. 2, pp. 1738-1746. https://doi.org/10.1021/acssuschemeng.6b02494

11. Di Cosimo, J.I., Díez, V.K., Xu, M., Iglesia, E., and Apesteguía, C.R., J. Catal., 1998, vol. 178, no. 2, pp. 499-510. https://doi.org/10.1006/jcat.1998.2161

12. Ndou, A.S., Plint, N., and Coville, N.J., App. Catal. A: General, 2003, vol. 251, no. 2, pp. 337-345. https://doi.org/10.1016/S0926-860X(03)00363-6

13. Dai, J. and Zhang, H., Sci. China Mater., 2019, vol. 62, pp. $1642-1654$. https://doi.org/10.1007/s40843-019-9454-x

14. Nikolaev, S.A., Golubina, E.V., and Shilina, M.I., Appl. Catal. B: Environmental, 2017, vol. 208, pp. 116-127. https://doi.org/10.1016/j.apcatb.2017.02.038

15. Nikolaev, S.A. and Krotova, I.N., Petrol. Chem., 2013, vol. 53, no. 6, pp. 394-400. https://doi.org/10.1134/S0965544113050071

16. Nikolaev, S.A., Chistyakov, A.V., Zharova, P.A., Tsodikov, M.V., Krotova, I.N., and Ezzgelenko, D.I., Petrol. Chem., 2016, vol. 56, no. 5, pp. 730-737. https://doi.org/10.1134/S0965544116080120

17. Zanaveskin, K.L., Lukashev, R.V., Makhin, M.N., and Zanaveskin, L.N., Ceram. Int., 2014, vol. 40, no. 10, pp. 16577-16580. https://doi.org/10.1016/j.ceramint.2014.08.013

18. Tjurina, L.A., Smirnov, V.V., Potapov, D.A., Nikolaev, S.A., Esipov, S.E., and Beletskaya, I.P., Organometallics, 2004, vol. 23, no. 6, pp. 1349-1351. https://doi.org/10.1021/om030633x 
19. Naumkin, A.V., Vasil'kov, A.Yu., Volkov, I.O., Smirnov, V.V., and Nikolaev, S.A., Inorg. Mater., 2007, vol. 43, no. 4, pp. 381-385].

https://doi.org/10.1134/S0020168507040103

20. Argyle, M.D. and Bartholomew, C.H., Catalysts, 2015, vol. 5, no. 1, pp. 145-269.

https://doi.org/10.3390/catal5010145

21. Sing, K.S.W., Everett, D.H., Haul, R.A.W., Moscow, L., Pierotti, R.A., Rouquérol, J., and Siemieniewska, T., Pure Appl. Chem., 1985, vol. 57, no. 4, pp. 603-619. https://doi.org/10.1351/pac198557040603

22. Sádaba, I., Granados, M.L., Riisager, A., and Taarning, E., Green Chem., 2015, vol. 17, no. 8, pp. 4133-4145. https://doi.org/10.1039/C5GC00804B

23. Besson, M. and Gallezot, P., Catal. Today, 2003, vol. 81, no. 4, pp. 547-559. https://doi.org/10.1016/S0920-5861(03)00153-6

24. Andrade, M.A. and Martins, L.M.D.R.S., Processes, 2020, vol. 8, article no. 1172. https://doi.org/10.3390/pr8091172

25. Zhu, M., Xu, L., Du, L., An, Y., and Wan, C., Catalysts, 2018, vol. 8, no. 12, article no. 638. https://doi.org/10.3390/catal8120638
26. Ivanova, A.S., Slavinskaya, E.M., Gulyaev, R.V., Zaikovskii, V.I., Stonkus, O.A., Danilova, I.G., Plyasova, L.M., Polukhina, I.A., and Boronin, A.I., Appl. Catal. B: Environomental, 2010, vol. 97, nos. 1-2, pp. 57-71. https://doi.org/10.1016/j.apcatb.2010.03.024

27. Senanayake, S.D., Zhou, J., Baddorf, A.P., and Mullins, D.R., Surface Sci., 2007, vol. 601, no. 15, pp. 3215-3223.

https://doi.org/10.1016/j.susc.2007.05.037

28. Royer, S. and Duprez, D., ChemCatChem., 2011, vol. 3, no. 1, pp. 24-65. https://doi.org/10.1002/cctc.201000378

29. Ellert, O.G., Tsodikov, M.V., Nikolaev, S.A., and Novotortsev, V.M., Russ. Chem. Rev., 2014, vol. 83, no. 8, pp. 718-732. https://doi.org/10.1070/RC2014v083n08ABEH004432

30. Hammer, B. and Nørskov, J.K., Adv. Catal., 2000, vol. 45, pp. 71-129. https://doi.org/10.1016/S0360-0564(02)45013-4

31. Chen, J., Li, Y., Lu, N., Tian, C., Han, Z., Zhang, L., Fang, Y., Qian, B., Jiang, X., and Cui, R., J. Mater. Chem. A, 2018, vol. 6, no. 46, pp. 23560-23568. https://doi.org/10.1039/C8TA08445A 